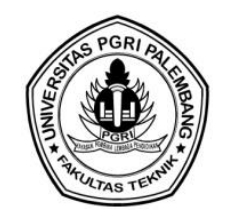

\title{
ANALISIS PENETAPAN HARGA JUAL UNIT RUMAH DENGAN METODE ANALISA TITIK IMPAS (PERUMAHAN BUKIT SENTOSA RESIDENCE \& GRIYA REVARI INDAH)
}

\author{
Ani Firda, Ahmad Fikri \\ Program Studi Teknik Sipil, Fakultas Teknik, Universitas Tridinanti Palembang \\ Coresponding Author, Email : ani.firda@gmail.com
}

\begin{abstract}
ABSTRAK
Dengan bertambahnya jumlah penduduk di Indonesia khususnya di Kota Palembang, maka kebutuhan masyarakat akan tersedianya sebuah tempat tinggal semakin meningkat. Hal tersebut berdampak pada semakin banyaknya kegiatan konstruksi hunian, terutama perumahan. Penelitian ini memaparkan penetapan harga jual unit rumah. Studi kasus perumahan Bukit Sentosa Residence dan Griya Pesona Borang. Penetapan harga jual dilakukan dengan metode analisa titik impas yang mempertemukan kurva biaya dan kurva permintaan. Berdasarkan analisa tersebut didapat harga jual Rp. 122.397.934,- untuk perumahan Bukit Sentosa Residence dan Rp. 120.736.618,- untuk perumahan Griya Revari Indah.
\end{abstract}

Kata Kunci : Analisa Titik Impas, Perumahan Bukit Sentosa Residence, Perumahan Griya Revari Indah.

\section{PENDAHULUAN}

Perumahan adalah kelompok rumah yang berfungsi sebagai lingkungan tempat tinggal atau hunian yang dilengkapi dengan prasarana lingkungan yaitu kelengkapan dasar fisik lingkungan, misalnya penyediaan air minum, pembuangan sampah, listrik, telepon, jalan, yang memungkinkan lingkungan pemukiman berfungsi sebagaimana mestinya.

Rumah adalah tempat untuk melepaskan lelah, tempat bergaul, dan membina rasa kekeluargaan diantara anggota keluarga, tempat berlindung keluarga dan menyimpan barang berharga, dan rumah juga sebagai status lambang sosial.Rumah adalah/struktur fisik terdiri dari ruangan, halaman dan area sekitarnya yang dipakai sebagai tempat tinggal dan sarana pembinaan keluarga (UU RI No. 4 Tahun 1992).

Kebutuhan akan rumah merupakan salah satu kebutuhandasar (home needs) bagi manusia setelah pangan dan sandang. Setiap individu manusia akan mengutamakan pemenuhan kebutuhan dasar daripada kebutuhan sekundernya.

Begitu pula dengan kebutuhan akan rumah, setiap orang akan berusaha memenuhikebutuhan akan rumah dalam setiap tingkat kehidupan masyarakat dengan memperhatikan selera dan kemampuan yang ada. Menurut pasal 5 ayat (1) UU No 4 tahun 1992 tentang perumahan dan pemukiman setiap Warga Negara mempunyai hak untuk menempati dan atau menikmati dan atau memiliki rumah yang layak dalam lingkungan yang sehat, aman, serasi, dan teratur. Masyarakat saat ini memiliki beberapa pilihan dalam memiliki rumah.Pilihan tersebut adalah dengan cara membangun sendiri atau dengan cara sewa, membeli secara tunai atau angsuran, hibah atau dengan cara lain yang sesuai dengan peraturanperundang-undangan yang berlaku.

Kota Palembang adalah Ibu Kota Provinsi Sumatera Selatan dengan luas wilayah 400,61 km2 yang dihuni sekitar 1.558 .494 jiwa dengan kepadatan penduduk 3.890 per km2. Palembang merupakan kota terbesar kedua di pulau Sumatera.

Seiring dengan bertambahnya jumlah penduduk di Indonesia khususnya di Kota Palembang, maka kebutuhan masyarakat akan tersedianya tempat tinggal semakin meningkat. Hal tersebut berdampak pada semakin banyaknya kegiatan konstruksi hunian, terutama perumahan. 
Dalam penentuan harga jual unit rumah pihak pengembang memiliki peranan yang penting. Sebelum menetapkan harga jual unit rumah, pihak pengembang perlu menghitung dengan cermat agar semua unit rumah pada perumahan terjual. Selain itu harga jual unit rumah yang ditetapkan dapat diterima oleh pengembang melebihi biaya-biaya yang dikeluarkan dan harga tersebut dapat juga diterima oleh konsumen. Oleh sebab itu harga jual adalah faktor utama dan wajib diperhatikan pihak pengembang perumahan karena harga jual merupakan acuan pertimbangan pemilihan rumah oleh pembeli, disamping berbagai fasilitas yang ditawarkan.

Harga jual perumahan merupakan unsur penting dalampengelolaan biaya proyek perumahan secara keseluruhan. Bila harga jual unit rumah yang terlalu tinggi, kemungkinan besar developer/ pengembangakan mengalami kerugian. Sebaliknya bila harga terlalu rendah akan menimbulkan berbagai masalah pada waktu pelaksanaan pembangunan perumahan. Untuk menentukan harga dasar proyek maka diperlukan alat bantu berupa analisis Financial Break Even Pointatau metode titik impas keuangan.

Menurut Toto (2013) perhitungan titik impas keuangan memberikan gambaran jumlah unit yang terjual saat sebuah proyek mencapai $\mathrm{NPV}=0$. Apabila perusahaan perumahan menginginkan sebuah proyek dengan nilai NPV positif, maka harga dasar suatu proyek harus di atas harga pada titik impas keuangan.

Berdasarkan latar belakang tersebut maka perlu dilakukan analisa penetapan harga jual unit rumah tipe 36 pada dua perumahan yaitu perumahan Bukit Sentosa Residence Talang Jering dan perumahan Griya Revari Indah Talang Kelapa.

\section{Tujuan Penelitian}

Tujuan yang ingin dicapai dalam penelitian ini adalah sebagai berikut:

1. Mengetahui biaya apa saja dan besarnya biaya yang harus diperhitungkan dalam penetapan harga jual rumah per unit di perumahan Bukit Sentosa Residence Talang Jering dan perumahan Griya Revari Indah Talang Kelapa.

2. Megetahui harga jual rumah untuk setiap unit rumah berdasarkan permintaan pasar dan analisa biaya dengan menggunakan Metode Analisa Titik Impas.

\section{Pembatasan Masalah}

Batasan masalah pada penelitian ini penelitian ini adalah :

1. Penelitian di lakukan di dua lokasi perumahan yaitu pada perumahan Bukit Sentosa Residence Talang Jering dan perumahan Griya Revari Indah Talang Kelapadengan jenis rumah subsisdi pemerintah dengan tipe $36 \mathrm{~m}$

2. Pengambilan data terbatas pada spesifikasi bangunan perumahan, dan daftar harga satuan pekerjaan mengacu padabasic price Kota Palembang Tahun 2015 - 2016. Perhitungan biaya belum termasuk biaya pekerjaan lingkungan perumahan (biaya jalan lingkungan perumahan dll).

3. Metode yang dipakai dalam menetukan harga jual unit rumah dalam perumahan yaitu Analisa Titik Impas.

\section{TINJAUAN PUSTAKA}

\section{Pengertian Perumahan dan Permukiman}

Dalam Undang-Undang Nomor 1 Tahun 2011 tentang perumahan dan permukiman, perumahan adalahkumpulan rumah sebagai bagian dari pemukimanbaik perkotaan maupun pedesaan, yang dilengkapi dengan prasarana, sarana, dan utilitas umum sebagai hasil upaya pemenuhan rumah yang layak huni. 
Permukiman yang dimaksud disini adalah bagian dari lingkungan hunian yang terdiri atas lebih dari satu satuan perumahan yang mempunyai prasarana, sarana, utilitas umum, serta mempunyai penunjang kegiatan fungsi lain di kawasan perkotaan atau kawasan perdesaan.

Sedangkan pengertian rumah dalam Undang - Undang Nomor 1 Tahun 2011 adalah bangunan gedung yang berfungsi sebagai tempat tinggal yang layak huni, sarana pembinaan keluarga, cerminan harkat dan martabat penghuninya, serta asset bagi pemiliknya.

\section{Elemen permukiman}

Permukiman terbentuk atas kesatuan antara manusia dan lingkungan di sekitarnya.

\section{Jenis Rumah}

Untuk menentukan luas minimum rata-rata dari perpetakan tanah harus mempertimbangkan faktor-faktor kehidupan manusianya, faktor alamnya dan pengaturan bangunan setempat. (C. Djemabut Blaang, Perumahan dan Permukiman, 1986: 28).

\section{Developer (Pelaku Usaha) Perumahan}

Menurut ketentuan Undang-Undang Perlindungan Konsumen Pasal 1 ayat 3, memberikan pengertian pelaku usaha, yaitu : setiap orang perseorangan atau badan usaha, baik yang berbentuk badan hukum maupun bukan badan hukum yang didirikan dan berkedudukan atau melakukan kegiatan dalam wilayah hukum Negara Republik Indonesia, baik sendiri maupun bersama-sama melalui perjanjian menyelenggarakan kegiatan usaha dalam berbagai bidang ekonomi.

\section{Kurva Analisa Permintaan}

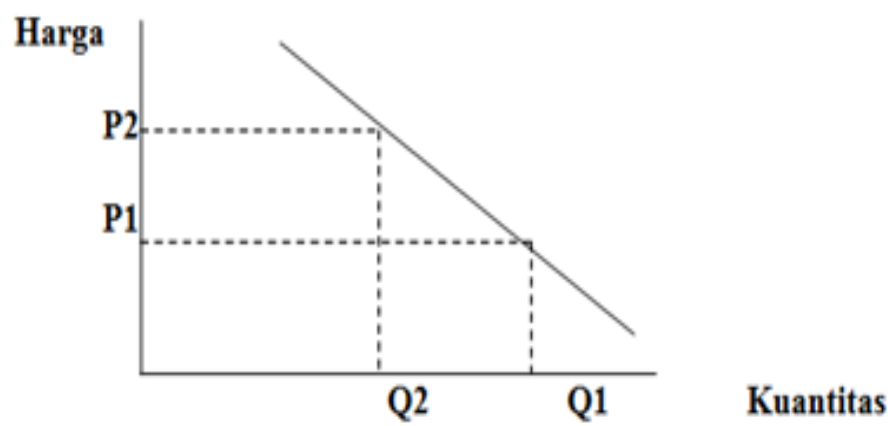

Sumber : Arsyad, (1999)

Gambar 1. Kurva Analisa Permintaan

Kurva permintaan merupakan suatu bagian dari fungsi permintaan yang menunjukkan hubungan antara harga produk dengan jumlah produk yang diminta.

\section{Kurva Analisa Biaya}

Untuk membuat kurva biaya, perlu dilakukan identifikasi biaya-biaya yang diperlukan dalam proyek pembangunan perumahan Bukit Sentosa Residence Talang Jering dan perumahan Griya Revari Indah Talang Kelapa, setelah itu dapat dibuat sebuah kurva biaya seperti gambar berikut: 


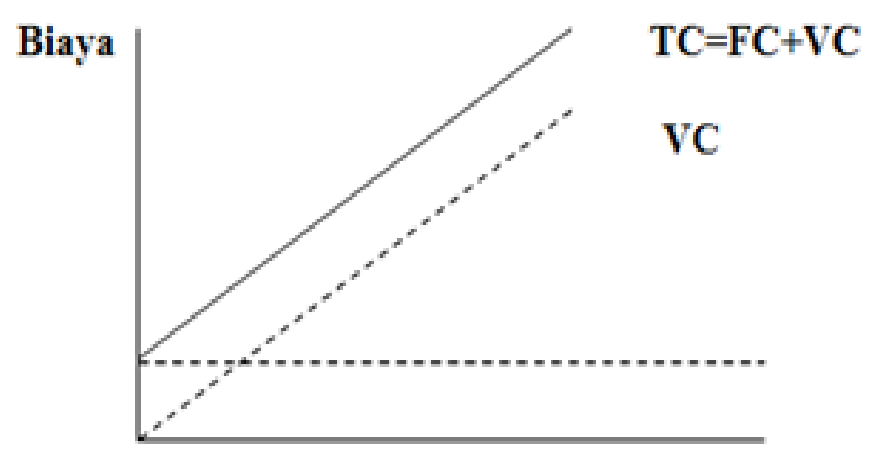

FC

\section{Volume}

\section{Sumber : Pujiawan I.N 2009}

Gambar 2. Kurva Analisa Biaya

\section{Metode Analisa Titik Impas}

Analisa Titik Impas dapat digunakan untuk membantu menetapkan sasaran perusahaan atau developer (pengembang). Pada Analisa Titik Impas, kita perlu menghitung seluruh biaya yang diperlukan.

\section{Menentukan Jumlah Sampel}

Salah satu metode yang digunakan untuk menentukan jumlah sampel adalah menggunakan rumus Slovin (Sevilla et. Al., 2007) sebagai berikut :

$$
n=\frac{\mathrm{N}}{1+\mathrm{N} \cdot \mathrm{e}^{2}}
$$

\section{Kualitas Perkiraan Biaya}

Untuk menghitung biaya total proyek, yang harus dilakukan pertama kali adalah mengidentifikasi lingkup kegiatanyang akan dikerjakan, kemudian mengkalikannya dengan biaya masing-masing lingkup yang dimaksud. Hal ini memerlukan kecakapan dan pengalaman.

\section{Rencana Anggaran Biaya}

Menurut Sugeng Djojowirono, 1984, rencana anggaran biaya merupakan perkiraan biaya yang diperlukan untuk setiap pekerjaan dalam suatu proyek konstruksi sehingga akan diperoleh biaya total yang diperlukan untuk menyelesaikan suatu proyek. 


\section{METODE PENELITIAN}

\section{Lokasi Penelitian Perumahan}

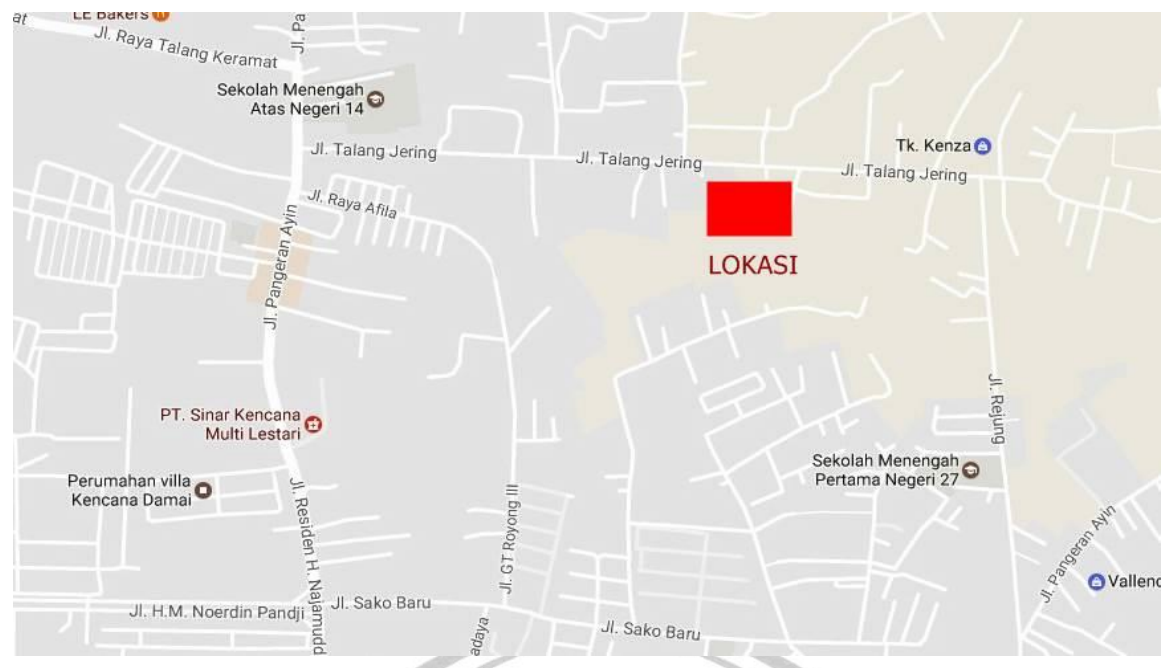

Gambar 3. Lokasi Perumahan Bukit Sentosa Talang Jering

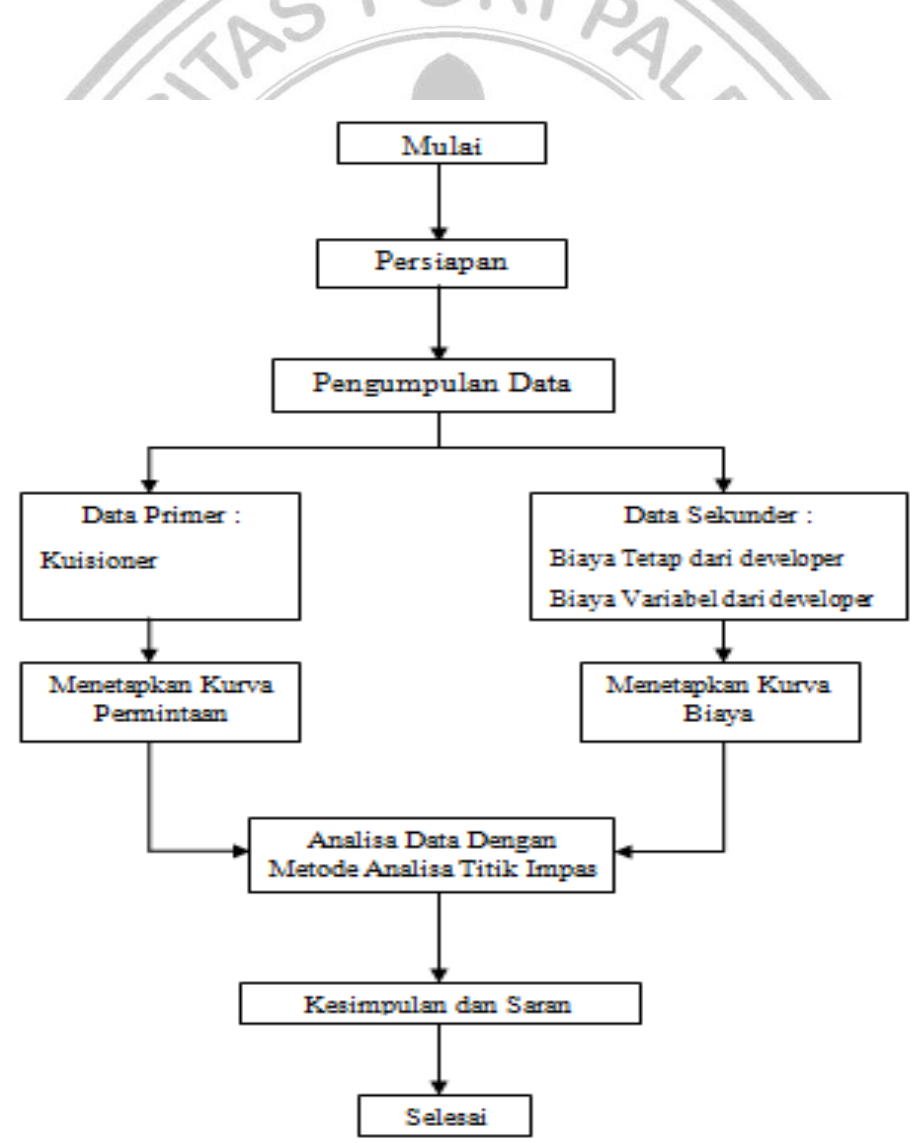

Gambar 4.Tahapan Pelaksanaan Penelitian

\section{Pengumpulan Data}

Metode pengumpulan data merupakan salah satu aspek yang sangat berperan penting dalam kelancaran dan keberhasilan dalam suatu penelitian. Pada penelitian ini menggunakan metode pengumpulan data berupa data primer dan data sekunder. 
a. Data Primer

Data primer adalah data yangdiambil langsung dari objek peneliti yaitu berupa pertanyaan yang disusun dalam kuisioner dan diberikan kepada pihak pihak calon pembeli atau calon debitur yang akan melakukan akad kredit di PT. Bank Tabungan Negara (Persero) Tbk, Kantor Cabang Palembang.

b. Data Sekunder

Data sekunder didapat dari beberapa referensi, antara lain PT. Pandega Pandu Perkasa dan PT. Revari Putra Pratama untuk mendapatkan data jumlah unit rumah,rencana anggaran biaya, dan site plan.

\section{Teknik Analisa Data}

Analisa pengolaan data menggunakan program microsoft exel, dan memakai metode Analisa Titk Impas.

\section{Analisa Data}

Dalam menetapkan harga jual unit rumah, digunakan metode Analisa Titik Impas, yang menggunakan persamaan MC=MR untuk mencari Q. MR (marginal revenue) adalah perubahan penerimaan / pendapatan untuk perubahan satu unit yang terjual, merupakan turunan dari TR. Sedangkan TR merupakan perkalian P x Q. MC (marginal cost) adalah perubahan biaya yang disebabkan perubahan satu unit rumah yang terjual.

\section{Analisis dan Pembahasan}

Pada penelitian ini diambil/dua sampel perumahan yaitu perumahan yang ada di kota Palembang dan perumahan di Kabupaten Banyuasin, perumahan yang pertama yaitu perumahan Bukit Sentosa Residence Talang Jering di Kabupaten Banyuasin dan perumahan yang kedua perumahan Griya Revari Indah Talang Kelapa di Palembang, perumahan Bukit Sentosa Residence Talang Jering yaitu perumahan yang berlokasi di Jalang Tering Kelurahan Kenten Laut Kecamatan Talang Kelapa Kabupaten Banyuasin.

\section{Analisa Permintaan}

Sampel yang dimasukkan pada data penelitian ini dalam menentukan analisa permintaan adalah sebanyak 45 responden diambil dari total seluruh responden yaitu 50 orang dengan latar pekerjaan yang berbeda yaitu PNS/Polri/TNI, Karyawan Swasta, Wiraswasta, dan lainnya, untuk penghasilan responden kisaran berpenghasilan Rp. 2.500.000,-s/d Rp. 5.000.000,-.

Tabel 1. Hasil Survei Kuesioner Setelah dilkali Nilai Probabilitas

\begin{tabular}{|c|c|c|c|c|c|c|}
\hline Harga (Rp) & pasti & Ingin & Mungkin & Tidak & Pasti & Total \\
\cline { 2 - 6 } & beli & Beli & bali & Ingin & Tidalk & \\
\hline 110000000 & 45 & 0 & 0 & 0 & 0 & 45 \\
\hline 120000000 & 23 & 15.75 & 0.5 & 0 & 0 & 39.25 \\
\hline 130000000 & 4 & 3 & 8.5 & 4.5 & 0 & 20 \\
\hline 140000000 & 1 & 3.75 & 2.5 & 5 & 0 & 12.25 \\
\hline 150000000 & 1 & 3 & 1.5 & 1.5 & 0 & 7
\end{tabular}




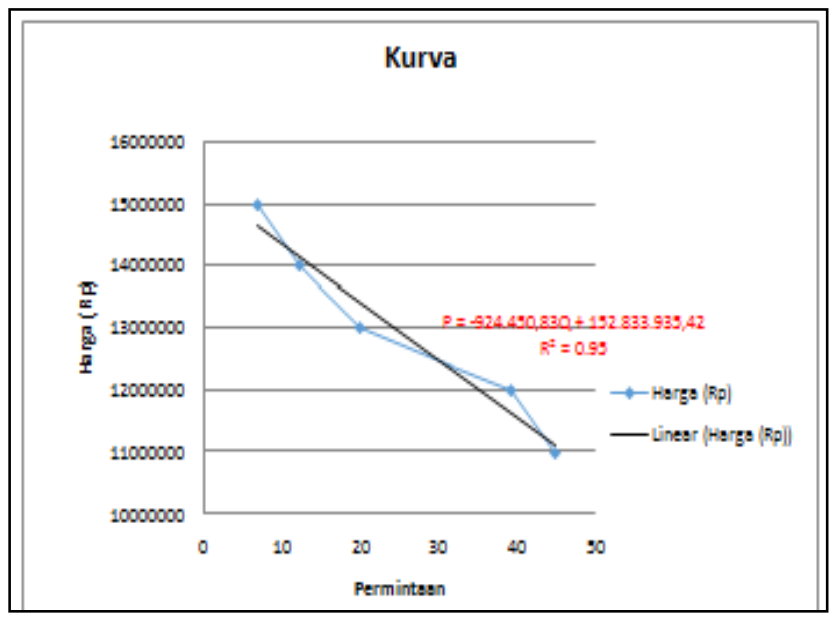

Gambar 5. Kurva Permintaan

\section{Analisa Biaya}

Dalam menentukan analisa biaya, biaya yang harus diperhitungkan dalam penetapan harga jual unit perumahan yaitu biaya tetap dan biaya variabel, analisa masing - masing biaya sebagai berikut :

\section{Biaya Tetap}

Biaya tetap adalah biaya yang tidak dipengaruhi oleh jumlah output atau volume produksi, data didapat dari keterangan developer yaitu terdiri dari

1. Biaya tanah

2. Biaya sertifikasi tanah

3. Biaya pembuatan jalan

4. Biaya pemasaran

5. Biaya Desain

\section{Analisa Biaya Tetap (FC) dan Biaya Variabel (VC) Pada Perumahan Bukit Sentosa Residence Talang Jering di Kabupaten Banyuasin}

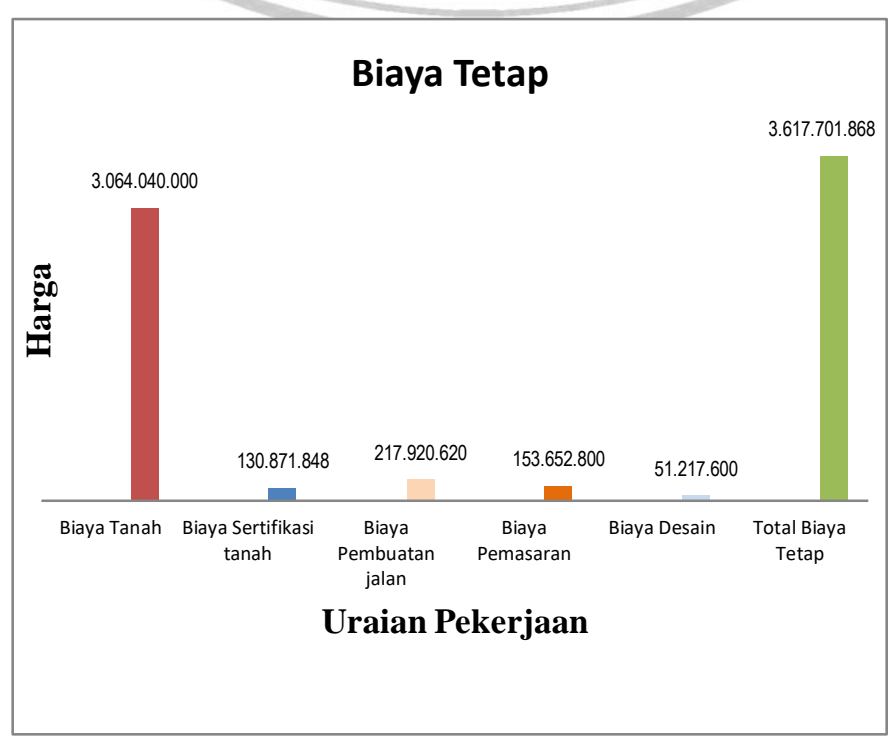

Gambar 6. Grafik Biaya Tetap (FC) Perumahan Bukit Sentosa Residence 


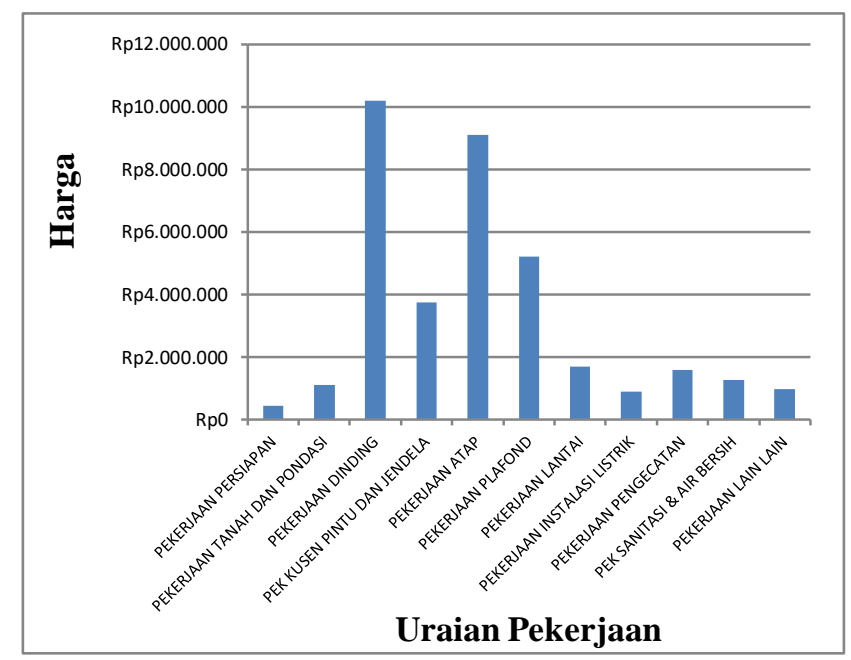

Gambar 7. Biaya Variabel (VC) Perumahan Bukit Sentosa Residence

\section{Penetapan Harga Jual Unit Rumah Dengan Metode Titik Impas}

Dengan demikian harga jual unit rumah berdasarkan analisa titk impas untuk mendapat keuntungan maksimum adalah Rp. 92.744.631,47,-- per unit dengan jumlah unit terjual optimum 65 unit.

\section{Analisa Biaya Tetap (FC) dan Biaya Variabel (VC) Pada Perumahan Griya Revari Indah Talang Kelapa Palembang}

Biaya variabel merupakan jenis biaya yang selalu berubah sesuai dengan perubahan volume penjualan dalam hal ini yang menjadi sampel yaitu $\mathrm{RAB}$ pembangunan satu unit rumah dari data developer / pengembang, dimana perubahannya tercermin dalam biaya variabel total.

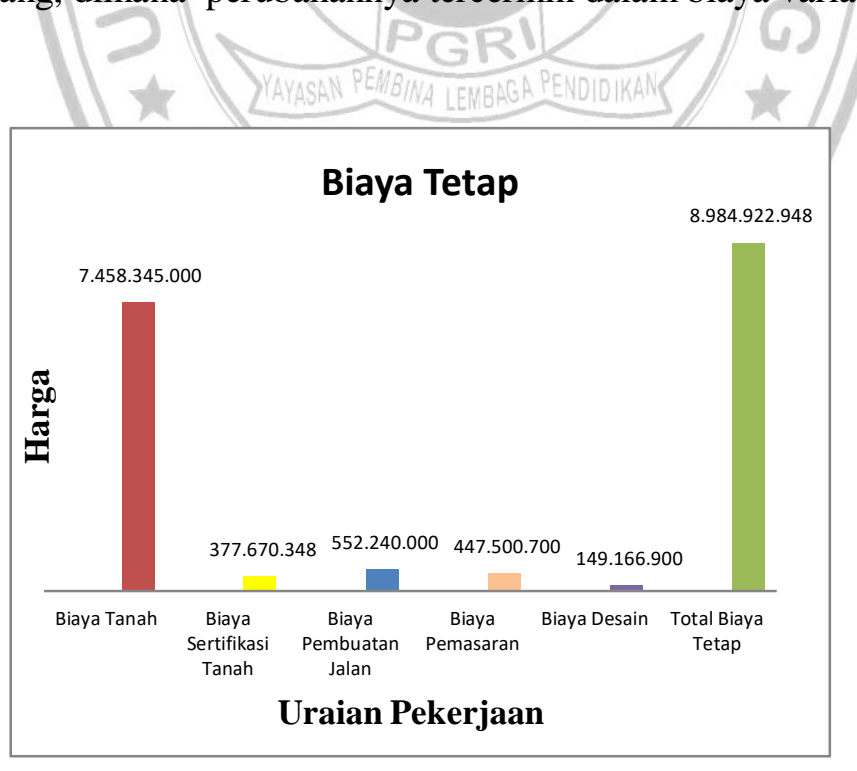

Gambar 8. Grafik Biaya Tetap (FC) Perumahan Griya Revari Indah 


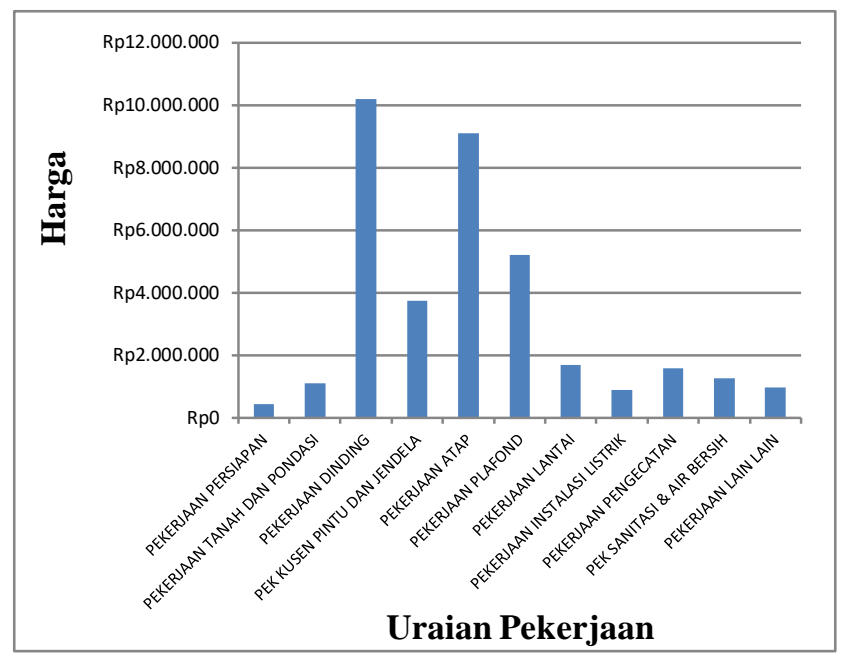

Gambar 9. Biaya Variabel (VC) Perumahan Griya Revari Indah

Dari data RAB diatas untuk biaya variabel (VC) perumahan Griya Revari Indah Talang Kelapa adalah Rp. 36.194.911,-

Maka :

$\mathrm{TC}=\mathrm{FC}+\mathrm{VC}$

$\mathrm{TC}=$ Rp. 8.984.922.948,- + Rp. 36.194.911,--

$\mathrm{TC}=$ Rp. 9.021.117.859,-

\section{Penetapan Harga Jual Unit Rumah Dengan Metode Titik Impas}

Dengan demikian harga jual unit rumah berdasarkan analisa titk impas untuk mendapat keuntungan maksimum adalah Rp. 93.669.082,3,- per unit dengan jumlah unit terjual optimum 64 unit.

Dari hasil perhitungan diatas maka harga jual tiap unit rumah tipe 36 perumahan subsidi Bukit Sentosa Residence Talang Jering adalah Rp. 122.397,934,-, untuk perumahan Griya Revari Indah Talang Kelapa Rp. 120.736.618, harga tersebut didapat dari gabungan biaya tetap, biaya variabel dan metode Titik Impas.

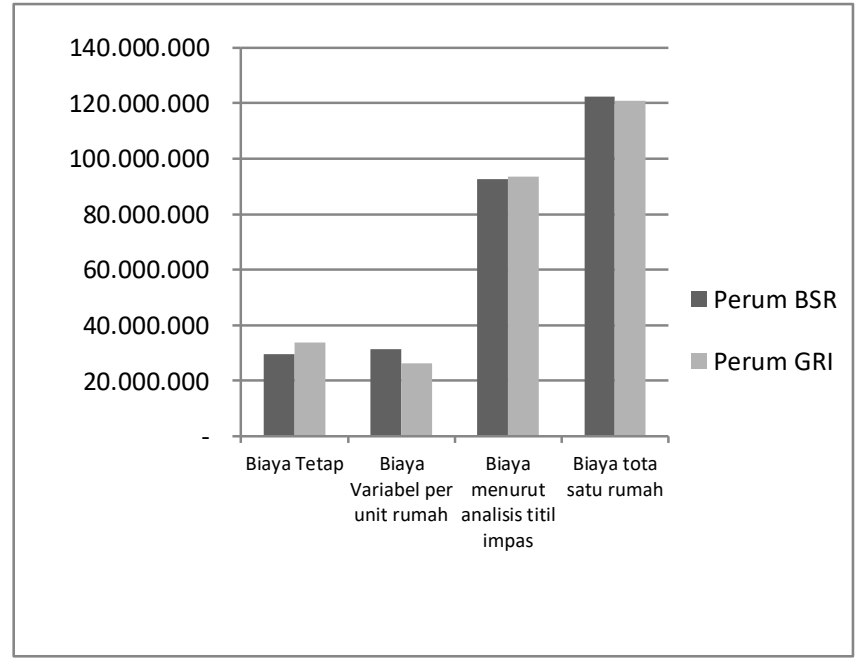

Gambar 10.Grafik Harga Jual Unit Rumah pada Masing-masing Perumahan 


\section{KESIMPULAN}

Berdasarkan hasil analisa yang dilakukan oleh peneliti, maka dapat diambil kesimpulan sebagai berikut :

1. Biaya yang harus diperhitungkan dalam penetapan harga jual rumah per unit pada perumahan Bukit Sentosa Residence Talang Jering dan perumahan Griya Revari Indah Talang Kelapa ialah biaya tetap dan biaya variabel. Biaya tetap meliputi biaya tanah, biaya sertifikasi tanah, biaya pembuatan jalan, biaya pemasaran dan biaya desain yang jumlahnya sebesar Rp. 3.617.702.868,- pada perumahan Bukit Sentosa Residence Talang Jering dan sebesar Rp. 8.984.922.948,-. Sedangkan besar biaya variabel pada perumahan Bukit Sentosa Residence Talang Jering yaitu Rp. 31,523,121,- dan pada perumahan Griya Revari Indah sebesar Rp. $36,194,911,-$.

2. Berdasarkan hasil penelitian dari analisa titk impas dapat disimpulkan bahwa harga jual unit rumah menurut permintaan pasar untuk perumahan Bukit Sentosa Residence Talang Tering sebesar Rp. 122,397,934 dan untuk perumahan Griya Revari Indah Talang Kelapa sebesar Rp. $120,736,618$

\section{DAFTAR PUSTAKA}

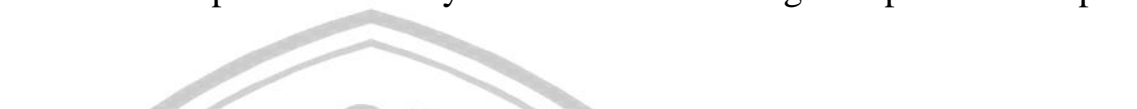

Arsyad, L.1999. Ekonomi Manajerial : Ekonomi Mikro Terapan untuk Management Bisnis. Yogyakarta : BPFE.

Bachtiar Ibrahim,2007, Rencana dan Estimate Real of Cost, cetakan keempat, Jakarta, 2007.

C. Djemabut Blaang, 1986, Perumahan dan Permukiman,

Iman Soeharto, 1995, Manajemen Proyek Dari Konseptual Sampai Operasional

Kotler, P.2005. Management Pemasaran Jilid 2. Jakarta : Erlangga

Miles, M.E. 2007. Real Estate Development 4th Edition. Urband Land Institude

Suparno Sastra M. dan Endi Marlina,2006 hal 29, Perencanaan dan Pengembangan Perumahan

Suparno Sastra M. dan Endi Marlina,2006 hal 37 Perencanaan dan Pengembangan Perumahan

Pujawan, I.N. 2009. Ekonomi Teknik. Surabaya : Guna Widya 